\title{
ANTROPONIMIA E TERRITORIO: SOBRE A DIFUSIÓN DOS APELIDOS EN GALICIA
}

\author{
Ana I. Boullón Agrelo
}

Instituto da Lingua Galega (USC)

A análise da distribución areal actual de certos apelidos deita luz sobre os seus procesos de difusión. Non se pode, nestes momentos, establecer áreas léxicas entre os apelidos, tendo en conta, por un lado, a gran dispersión que presentan os datos dialectométricos no que respecta ao léxico (véxase, neste mesmo volume, Álvarez/Dubert/Sousa), e, por outro lado, o estado actual das investigacións antroponímicas. Ademais, hai que ter en conta a especificidade dos apelidos con respecto ao léxico común, fundamentalmente o seu carácter hereditario e a súa relación estreita cos portadores, que os fan especialmente sensibles aos movementos de poboación. E, por último, a influencia que poden ter factores sociopolíticos e legais, que determinan, en ocasións, a súa transformación (no caso das formas castelanizadas, por exemplo).

Neste traballo examinarei algúns apelidos que presentan características distintas, para ver ata que punto a súa conformación (proceder dun topónimo, do léxico común ou dun patronímico) e o seu foco de irradiación inicial (ser polixenéticos ou proceder dun único punto localizado) poden condicionar a súa difusión. Así, exemplificarei con dous apelidos detoponímicos con orixe nun único punto localizado (Boullón, Xove), cun de orixe lexical pexado pola interdición (Cochón) e con outros polixenéticos que teñen a súa orixe nun topónimo (Eirís/Eiriz), nun termo do léxico común (Lonzao, Louzán) e mais nun patronímico (Martís, Martíns). Tamén se terán en conta as formas castelanizadas correspondentes (Lozano, Martinez). Nalgún deles comprobarase ata que punto amosan relación con diversos fenómenos fonéticos (o seseo implosivo: Eirís/Eiriz), ou morfolóxicos (terminación -án/-ao: Louzao/ Louzán,-ins/-is: Martins/Martís).

R. Álvarez, F. Dubert, X. Sousa (eds.): Lingua e Territorio Santiago de Compostela: ILG/CCG, 2006, 235-255 ISBN 84-96530-20-5 
Os datos están tirados do Censo de persoas vivas do Instituto Galego de Estatística correspondente ao ano 2002, que conta con case cinco millóns e medio de ocorrencias que corresponden a 50.000 formas diferentes, das 2.750 .684 persoas que están censadas en Galicia. A vinculación de cada apelido co seu lugar de residencia permítenos establecer os mapas da súa distribución actual. As atestacións históricas tómanse dos materiais da Sección de Onomástica do Instituto da Lingua Galega, que reúne unhas 35.000 cadeas onomásticas de distintas fontes documentais de toda Galicia e unhas 6.000 dos Catastros da Ensenada, do século XVIII. Finalmente, para a toponimia de Galicia, é moi útil o elenco da toponimia oficial na páxina web da Xunta de Galicia, http://www.xunta.es/nomenclator/index.htm; tamén existe elenco impreso (Nomenclátor de Galicia 2003).

\section{ApELIDOS DETOPONÍMICOS}

Os apelidos procedentes dos topónimos maiores son os que máis claras evidencias ofrecen da expansión dun apelido, pois indican de maneira clara o foco de orixe. A partir de aí pódese indagar sobre as causas desas rutas, que normalmente son comúns, pois os apelidos viaxan de maneira lóxica e intelixible historicamente: igual cós homes, marchan das montañas e das rexións menos fértiles e son atraídos cara a zonas urbanas, seguindo o movemento dos ríos e das vías de comunicación (Büchi 1998: 12-13).

Os exemplos que se expoñen a seguir mostran a distribución cartográfica dos apelidos polos concellos segundo os datos porcentuais en relación aos apelidos totais en cada concello. Creo que é máis significativa esta cifra porcentual, posto que os números absolutos reflicten a distorsión dos núcleos de maior peso demográfico (as cidades): as maiores concentracións dos apelidos vense en ocasións nos centros inmigratorios, sen que isto signifique automaticamente o punto de procedencia.

1. O apelido Boullón (399 ocorrencias) procede dun topónimo de etimoloxía pouco clara ${ }^{1}$ situado na parroquia de San Miguel de Boullón,

1 O correspondente francés, Bouillon, ponse en relación co lat. BULLIRE ou cun nome persoal BuLLiUs. Para o galego, presenta unha dificultade fonética: o ditongo non etimolóxico, documentado nas atestacións galegas máis antigas. No léxico común, 
do concello de Brión. Exemplifica bastante ben o que levamos dicindo dos apelidos toponímicos, pois a súa expansión irradia desde o seu núcleo de orixe cara ás zonas circundantes.

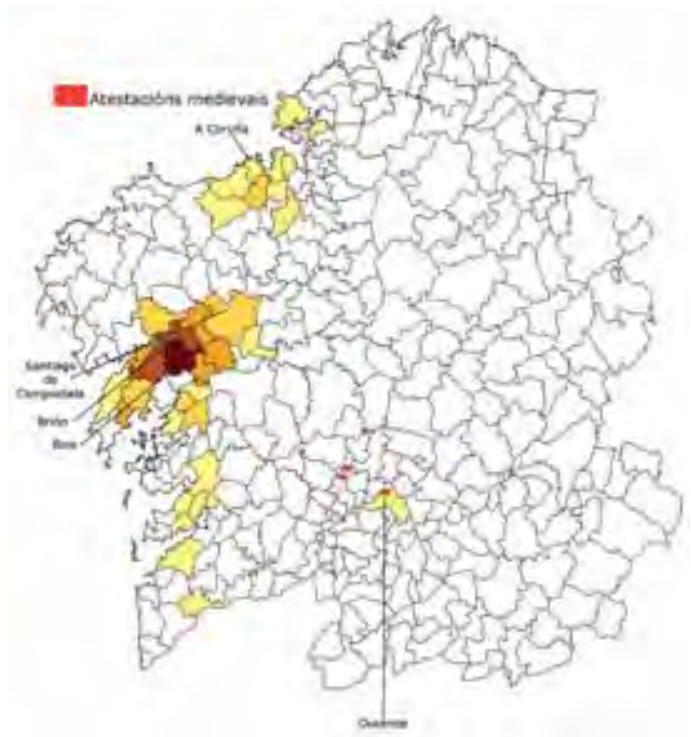

Mapa 1. Distribución actual do apelido Boullón

Hoxe en día, a maior densidade do apelido está concentrada no concello de Rois, limítrofe con Brión, e na área lindeira, con dous polos naturais de atracción: por un lado, a cidade de Santiago, e por outro, a península do Barbanza. Polo resto, os seus portadores seguiron as vías de comunicación: cara ao sur, ao longo da estrada N-550, que chega a

boullón e bullón alternan para referirse a 'borbotón' (véxase o DD), e tense posto en relación co lat. BULLA ('bochiga, protuberancia', en posible conexión con boulla 'bugallo', bulleiro 'lameira'. Vid. Navaza 1998: 61), aínda que son palabras de escasa circulación; quizais o ditongo se deba á forza expresiva da palabra. A variante monotongada Bullón (así mesmo de orixe toponímica, pois existe O Bullón en Monfero-Co), que tamén se rexistra como apelido, é moito menos frecuente: só 16 ocorrencias, 13 das cales están no concello da Coruña, é dicir, próximas á localización do topónimo. Por último, tamén se podería considerar como orixe un topónimo de posesor, pero non atestamos ningún *BAULIO (paralelo a Braulio, que deu lugar a Brollón [A Pobra do Brollón-Lu], con monotongación, e a Broullón [Moaña e Meaño-Po], sen ela en Schulze [1966: 350] hai un BULlonius, de estirpe celta, pero volve a haber o problema do ditongo). 
Vigo, e cara ao norte, en torno á cidade da Coruña. Fóra destas áreas, o único lugar onde se atopan atestacións é noutra capital de provincia, Ourense. Estes portadores (5) poden proceder de calquera dos lugares anteditos, ou quizá non: curiosamente, as únicas atestacións medievais que documentamos proceden de Ourense ou arredores: atéstase un Iohanni Boulion en 1251 (DocCatOurense 213); P. Boullon, un veciño de Seoane de Arcos (O Carballiño-Ou), véndelle un agro ao abade de Oseira en 1262 (CDOseira 854); uns anos despois, en 1293, Eanes dito Boullon compra un herdamento na mesma freguesía (CDOseira 1172). Por último, en 1459, documéntase un «Diego de Bullón, notario», na cidade de Ourense (Devanceiros, II 359).

2. Outro bo exemplo de expansión a partir dun punto localizado constitúeo Xove (382 ocorrencias), probablemente do xenitivo do nome persoal latino Jovius ${ }^{2}$.

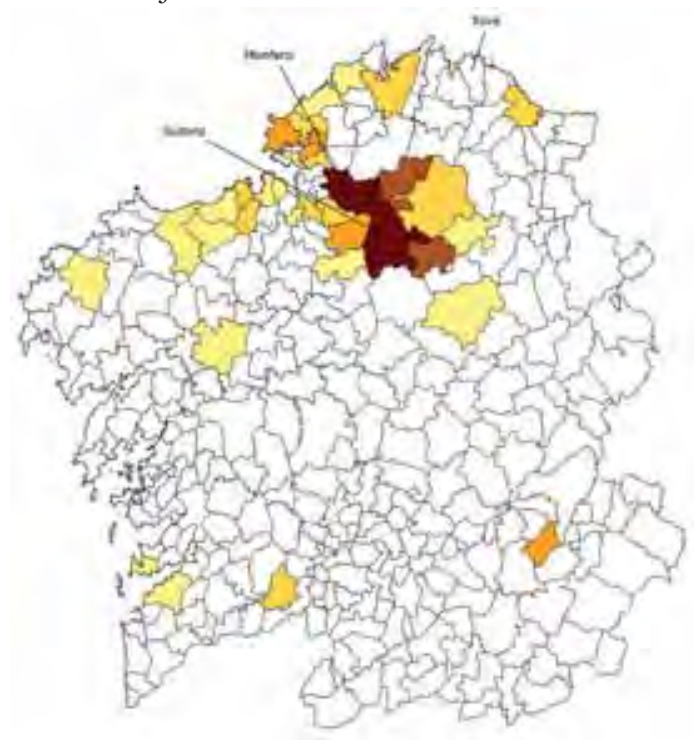

Mapa 2. Distribución actual do apelido Xove

A mancha máis escura está ocupando os concellos de Guitiriz e Monfero e, de forma decrecente, Begonte e Xermade. Pode parecer estraño que non haxa atestacións no concello homónimo (Xove), pero é

2 Máis ca do acusativo Iovem de Xúpiter, segundo Moralejo (1977: 39). 
que o apelido non procede xeograficamente de alí, senón de dúas aldeas da parroquia de Santa María de Labrada, do concello de Guitiriz, Xove Novo e Xove Vello. A partir de aí, os seus portadores dirixíronse sobre todo cara á área da Coruña e Ferrol. Tamén hai mostras noutras cidades de Galicia (Santiago e Vigo). A súa presenza en lugares como Trives $(\mathrm{Ou})$ ou A Cañiza (Po) probablemente teña que ver coas peripecias vitais dos seus portadores máis ca con outras variables previsibles.

\section{APELIDOS DELEXICAIS}

Os apelidos delexicais ou apelativos fan referencia a unha característica da persoa. O grupo máis compacto dentro deles é o dos profesionais, e despois os que fan referencia a trazos físicos ou psicolóxicos do portador. En principio, a maioría deles foron alcumes, e todos os que coñecemos este sistema de denominación, que aínda segue vivo en grandes áreas de Galicia -especialmente nas menos urbanas-, sabemos o caprichoso das motivacións que poden dar lugar a apelativos; como consecuencia, case todos os campos léxicos se ven aquí representados. Estes son, obviamente, os que máis interesan para a historia lexical, pois moitas veces se documentan formas que xa están mortas na lingua común, ou das que só quedan residuos dialectais moi restrinxidos xeograficamente.

O que escollemos para este epígrafe pertence ao grupo dos caracterizadores, fai alusión a calidades negativas, e neste caso a carga semántica afecta á súa difusión.

O apelido Cochón é especialmente interesante porque introduce unha variable que, no que respecta aos apelidos delexicais, é determinante xa non para a súa difusión e propagación, senón para a súa propia supervivencia. Ese factor é a interdición. Xa noutro momento falei de raposo e golpe (Boullón 2002), formas lexicais con cadanseu reflexo antroponímico que proporcionan información sobre a expansión lexical. Nese caso, viamos como por toda a Romania a forza da interdición ocasionaba o cambio continuo de ítem lexical para nomear un animal que era innomeable, posto que significaba unha ameaza para a economía de subsistencia e, por tanto, para a propia supervivencia.

$\mathrm{Na}$ Península Ibérica hai relativamente poucos apelidos malsoantes, especialmente de compararse con outras zonas, como Italia, onde 
son moito máis abundantes. Isto adóitase explicar como consecuencia, por un lado, da ausencia dunha auténtica regulación legal do nome ata hai moi pouco tempo (en realidade, ata a lei do Rexistro Civil de 1957, segundo Luces Gil 1977); por outro lado, ao costume, propio da Península e peculiar con respecto aos outros países europeos, da imposición dun dobre apelido, o do pai e o da nai. Iso permitía escoller e «eliminar así los menos halagüeños» (Schmid 1998: 145):

Claro que en la Edad Media debieron de vivir en Asturias también algunos tuertos, mancos, tontos, indecentes, personas pequeñas, débiles y pusilánimes. Los apellidos, en cambio, nos hacen creer que (casi) todos eran delgados, galantes, corteses, lozanos y bravos (Schmid 1998: 146).

No campo semántico que imos tratar, o do porco, foi tamén esa interdición a que motivou a profusión de nomes cos que está rexistrado: no Atlas Lingüístico de Galicia ( $A L G a$, do Instituto da Lingua Galega) rexístrase case unha decena: porco, marrao, quino, rancho, chino, cocho, gocho, curricho. O seu uso antroponímico vén derivado das características asociadas a este animal, especialmente a sucidade. En portugués antigo, cochom valía para 'homen vil, ordinário, grosseiro' e cochõa 'mulher do povo' (apud Kremer 1971: 158). Amais destes significados, cando son usados como prenomes puideron ser nomen humilitatis, relativamente frecuentes entre os primeiros cristiáns; en todo caso, as atestacións galegas son sempre de segundos nomes. Os derivados de porco e cocho están atestados con uso antroponímico desde a Idade Media por toda a Península Ibérica ${ }^{3}$.

Expomos a seguir as seguintes atestacións medievais galegas:

- De cocho e derivados

Gundisalui Coche [a.1187 TSobrado II 402]

Eluyra Cochjña do Araño [a.1457 LNotasRianxo 307]

Petro Cochon [a.1220 Toxosoutos cit. por Rivas 1991: 410]

Petrus Cocha de Uilla Selam [s.a. TLourenzá 122]

- De porco e derivados ${ }^{4}$

Munnio Porco [a.1069 TCelanova 752]

3 En Cataluña atéstanse tamén derivados de PorCELlus, Porcel(l), Pursell, Porsel, coma o port. Porcêlo.

4 O sufixo -allo de porcallo, á parte do significado pexorativo, debíao ter tamén diminutivo, como se parece inferir deste exemplo portugués: «Martinus Petri Porcalo, filius de Martino Porca», a. 1258 (apud Kremer 1971: 156). 
Petrus Martini cognomento Porcaliario [a.1165 TSobrado I 451]

Petrus Porcalio [a.1167 TSobrado I 535]

Iohannes Porcalio [a.1206 TSobrado II 263]

Joan Porcallo = Joan Porqallo [a.1428,1433 PadrónsOurenseXV 17,32]

- Co significado 'porco pequeno'

Jua $<$ n $>$ Leito $<n>$ [15.1404(or.) CDFerreira 119]

Fernandus Bacuru [a.1165 TCelanova 189]

Dominicus Baccurus [a.1231 TSobrado II 172]

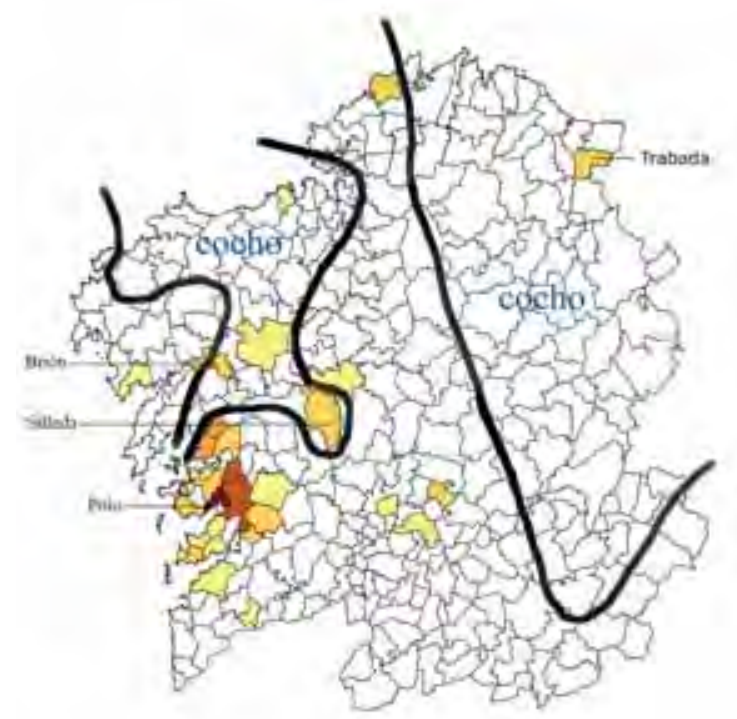

Mapa 3. Distribución actual do apelido Cochón e isoglosas da forma léxica cochó (ALGa)

De todos estes, só subsistiron como apelidos Leitón (con 131 ocorrencias), Porca (con 211) e Cochón, o máis frecuente de todos, con 584 ocorrencias.

Presenta a súa máxima concentración no concello de Poio, e está repartido nas áreas circundantes, con algunhas excepcións. A extensión desta forma é interesante porque, se a cruzamos coa área lexical de cocho (mapa confeccionado a partir de material inédito: cuestión 1667 do ALGa 'cerdo, -a, porco, $\left.-\mathrm{a}^{\prime}\right)^{5}$, veremos que, fóra dos concellos de

5 Agradézolle a Mónica Ares a súa amabilidade ao confeccionarme o mapa correspondente e tamén a Xosé Afonso Álvarez a súa axuda coa confección técnica dalgúns mapas. 
Silleda, Brión e Trabada (as concentracións nas cidades son menos significativas), todas elas se atestan en zonas onde non se utiliza cocho como voz común. Non parece, pois, moi aventurado pensar que a forma Cochón subsistiu nesa área porque, ao non utilizarse como voz común a forma cocho, evidentemente ningún derivado seu sería interpretado como forma malsoante.

\section{APELIDOS POLIXENÉTICOS, TRAZOS DIALECTAIS E ESTANDARIZACIÓN}

A distribución xeográfica actual dos apelidos pode iluminar diferentes aspectos da evolución fonética ou sobre os procesos de estandarización e da castelanización. Os casos aquí examinados son apelidos polixenéticos, quérese dicir, con orixe en diversos puntos. Isto é o que comparten, pois pertencen a grupos diversos: un é detoponímico (Eiria), outro delexical (Louzao) e o último patronímico (Martíns).

1. O topónimo Eiriz (ou Eirís) vén do nome persoal de orixe xermánica Agericus, en xenitivo (HGNB 5.10), como resultado probable dunha elisión da primeira parte do sintagma villa Agerici, como tantos outros topónimos galegos. A repartición dos apelidos con -z e -s é practicamente simétrica, pois teñen un número de ocorrencias moi similar: 638 e 531, respectivamente. Todas elas teñen orixe en diversos topónimos homónimos: Eiriz na Estrada (Po), Chantada e Folgoso do Courel (Lu), e Eirís en Oroso, Oleiros, Arteixo (Co) e O Porriño (Po).

As atestacións medievais correspóndense en parte tamén con apelidos actuais:

Petro Eiriz de Sancta Eolalia (10.[942-977] TCelanova 225)

Baltario Eiriz [fillo de Ericus Aulfiz] (10.[942-977] TCelanova 224)

Aluito Eiriz (11.[1020-1052] TSamos 83)

Eylo Eiriz = Eilo Eriz (12.1105 TCelanova 163, 164)

villa Eiriz (a.1168 TSamos 212-3)

molinum de Uillanoua discurrente riuulo Eiris (a.1225 CDRamirás 192-193)

Se superpomos o mapa do seseo implosivo vemos que as formas de Eirís están situadas dentro da área actual con $-s$ final, mentres que as que teñen $-₹$ final non só se corresponden coa área de $-₹$, senón que penetran na outra. Non é estraño, porque a forma con -zé máis etimolóxica, e por iso perdura mesmo en zonas onde esta grafía xa non 
se corresponde coa pronuncia moderna. Podemos considerar a outra como innovación, e de aí que se axuste máis á súa fronteira.

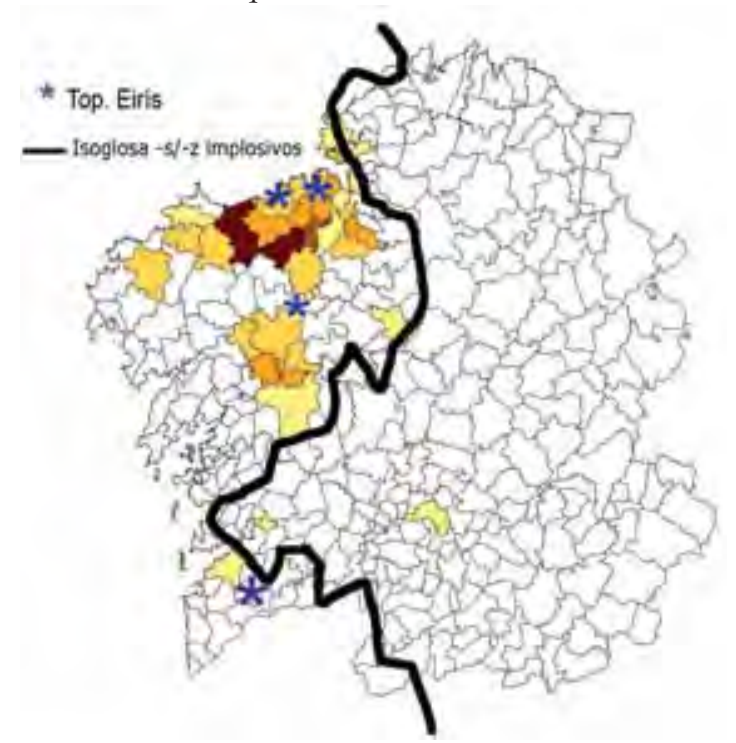

Mapa 4. Distribución actual do apelido Eirís

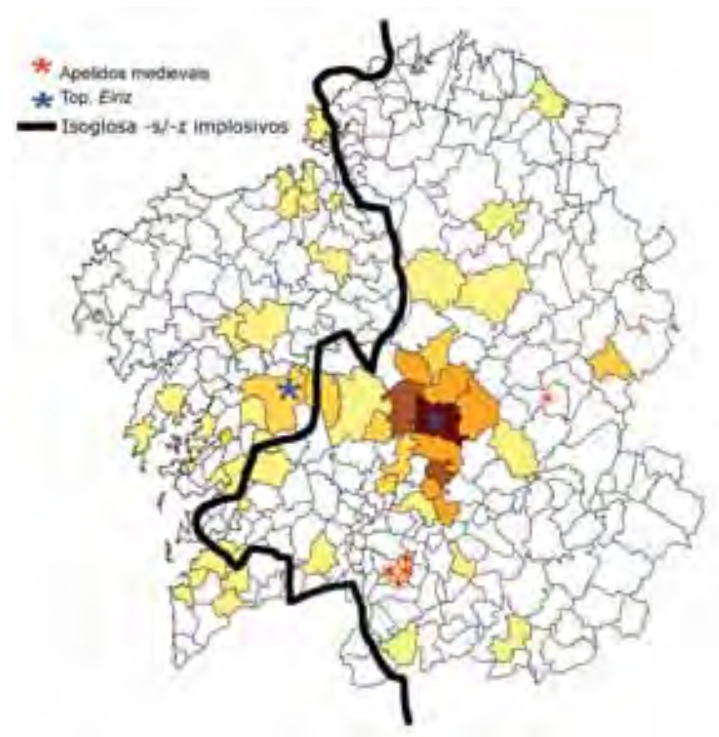

Mapa 5. Distribución actual do apelido Eiriz. 
2. Lonzao, Louzán e Lozano trátase dun apelido con orixe nun alcume que outorga calidades positivas ao seu portador (vén dun hipotético *LAUTIANUS, derivado do latín LAUTUS 'suntuoso'), na área semántica doutros semellantes, coma Gallardo, Viz̧oso, Garrido ou Feito. Aínda que actualmente está en desuso no léxico común (de feito, apenas ten respostas no $A L G a$ ), na Idade Media gozou de vitalidade por toda a Península, como así nos atestan os apelidos sobreviventes (port. Loução, Louçã, cast. Loz̧ano) (Kremer 1974/75: 191). Podémolo documentar desde o século XII en distintas coleccións documentais de Galicia, que presentamos por orde cronolóxica:

Iohannes Louzanus (s.a. TSobrado II 274)

Petrus Lauciano (a.1190 TSobrado I 217)

I. Lauzano (a.1228 DocCatOurense 114)

Iohanne Louzano (a.1235 TCaaveiro 334)

Iohanni dicto Louzano (a.1247 DocCatOurense 192)

Gonçaluo Loução de Tarrio (a.1336 DocUnivSantiago 158)

Aras Louçãao (a.1386 DocUnivSantiago 259)

Pero Loução scripuã (a.1401[1414-150] TumboBieitoSantiago 42)

Pedro Louça (a.1434 CDMaia 64 [Cabanas])

En port., Loução (Machado 1984: s.v.), desde 1258 (Lauzani, Lauzano, Louzano, Louzao).

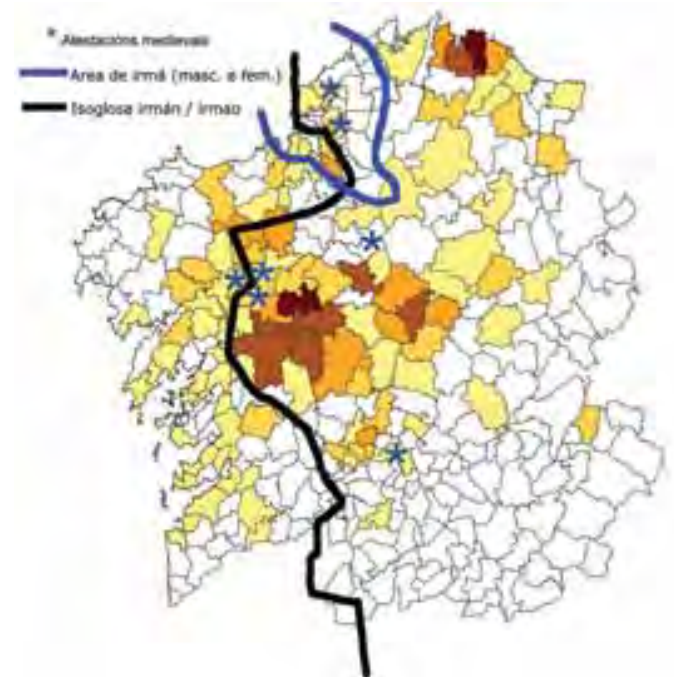

Mapa 6. Distribución actual do apelido Louzao e isoglosas da terminación morfolóxica -án/-ao ( $A L G a)$ 
Pois ben, este é un caso típico de apelido de orixe lexical polixenético, isto é, con orixe simultánea en diversos sitios, como demostran os documentos antigos. Consecuentemente, está bastante repartido por toda Galicia. Amais da información que nos proporciona o apelido da súa área na Idade Media, hoxe en día hai outros dous resultados deste étimo: Louzán, co resultado -án da terminación -ANUS, e o castelanismo Lozano, distribuídos en distintas proporcións:

\section{Número de ocorrencias modernas}

$\begin{array}{ll}\text { Louzao } & 1.698 \\ \text { Louzau } & 10 \\ \text { Louzán } & 730 \\ \text { Lozano } & 3.032\end{array}$

A segunda forma patrimonial, Louzán, non se documenta na época medieval; as atestacións localizadas máis antigas son do séc. XVIII, procedentes do catastro do Marqués da Ensenada e situadas en Santiago:

Maria Antonia Lou₹an ([costurera y planchadora] a.1752 CatastroSantiago 153) Francisco Louzan ([labrador] a.1752 CatastroSantiago 168)

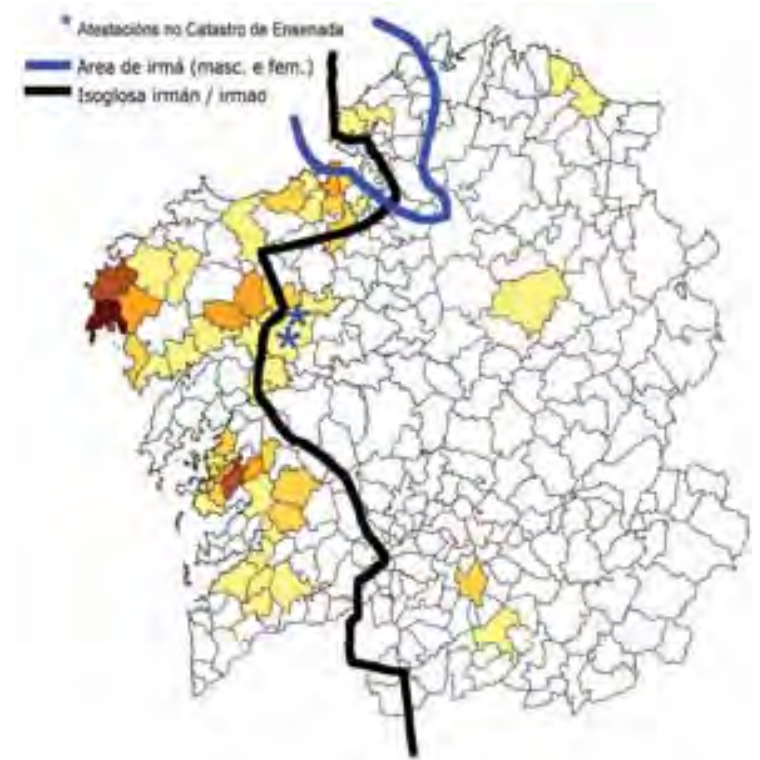

Mapa 7. Distribución actual do apelido Louæán e isoglosas da terminación morfolóxica -án/-ao (ALGa) 
A maior densidade do apelido Lou₹án dáse nesa área occidental da provincia da Coruña en que non se documentaba Louzao; hai tamén algunhas áreas de concorrencia nas comarcas de Santiago, Vigo e A Mariña. Se se atende á terminación e se superpón o mapa morfolóxico do $A L G a$ correspondente, obsérvase que as manchas están situadas en practicamente todos os casos dentro dos límites da isoglosa que delimita a solución -án. Isto non significa que a repartición dos apelidos Louzán/ Lonzao se corresponda coa área dialectal, xa que, ao facer o mesmo co mapa de Louzao compróbase que, se ben as maiores densidades están dentro da zona de -ao, hai tamén moitas atestacións ao occidente desa área, e tamén na que actualmente ten como resultado -áa (* Lou₹âa $)$.

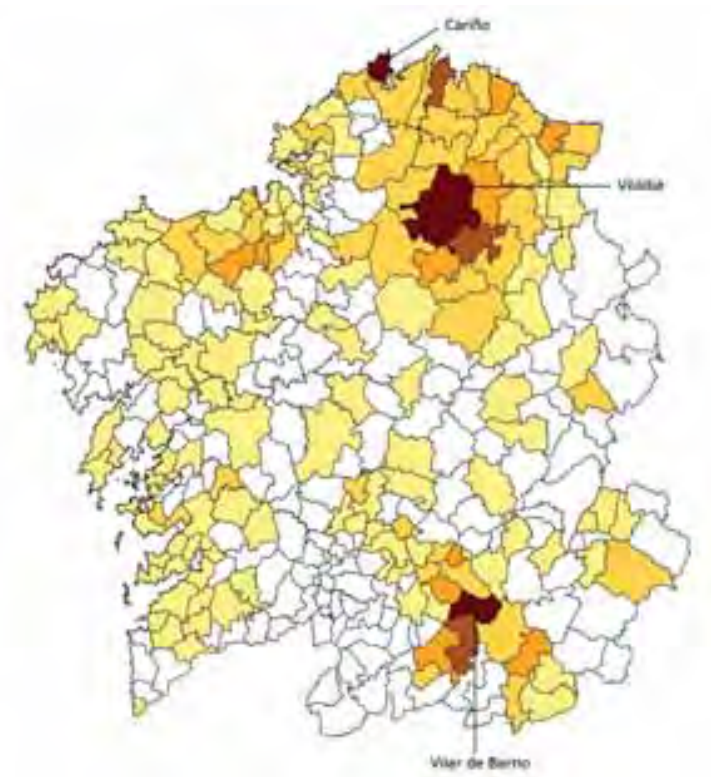

Mapa 8. Distribución actual do apelido castelanizado Lozano

Isto móstranos que os apelidos, se ben reflicten as realidades dialectais, fano de maneira menos directa cós datos contemporáneos, sobre todo no que se refire aos límites modernos de certos fenómenos fonéticos e morfolóxicos (quizais máis que aos léxicos), ao testemuñarnos non só a realidade actual, senón tamén situacións pasadas. E isto é así porque hai que ter en conta outra variable, que é a permanencia das grafías etimolóxicas. A forma Lou₹̨a é descendente gráfica directa da 
medieval, tendo en conta que a partir do XVI os escribas prescindiron totalmente dos sinais de abreviación e, por tanto, tamén dos símbolos que no seu momento significaran resonancias nasais. Ademais, neste caso axustábanse á realidade fonética, pois a nasalidade resolveuse, desde moito antes (hai testemuños escritos desde o XIII), nos resultados modernos. Por tanto, debemos interpretar a forma Louzao como directamente procedente das medievais, Louzán como unha innovación, que reflectía na escrita as formas reais nas zonas occidentais e, finalmente, Lozano, a forma castelanizada, outra innovación, pero de causa e datación distinta.

O castelanismo é moito máis frecuente cás formas patrimoniais (3.023 ocorrencias fronte a 719 e 1.685), o que nos mostra que é un dos ítems en que a presión do castelán foi moi efectiva. Non se trata, desde logo, de inmigracións de casteláns portadores deste apelido. A propia composición demográfica de Galicia permite doadamente descartar isto: país tradicionalmente emigratorio, ata hai moi pouco tempo non contaba cunha compoñente inmigratoria de importancia. Os castelanismos nos apelidos que hai actualmente teñen un peso cuantitativo considerable (ao redor dun 15\% no conxunto dos apelidos: vid. Boullón 2005), e pódense considerar como o froito da presión oficializadora exercida desde o propio tempo de creación dos rexistros, en maior ou menor grao, é dicir, desde o século XVI. Os testemuños máis antigos da forma Lozano que nos constan veñen do Catastro de Ensenada, e aparecen nas cidades de Santiago e da Coruña:

Francisco Lozano ([escrivano publico y real] a.1752 CatastroSantiago 93)

Gregorio Lozano Santiso ([escrivano real] a.1752 CatastroCoruña 97)

Se observamos a distribución xeográfica da forma castelanizada, o primeiro que vemos é que está repartida practicamente por todo o país. En segundo lugar, que as áreas de maior concentración correspóndense en boa medida coas áreas en que non había atestacións de Lonzao: sueste de Ourense, nordeste de Lugo. Isto significa que, se ben nalgunhas áreas conviven a forma propia co castelanismo (como nas áreas metropolitanas da Coruña, Ferrol e Vigo, onde tamén hai Louzán), noutras hai unha distribución complementaria de ambas as dúas. Nas devanditas zonas de Lugo e Ourense as formas propias foron practicamente varridas polas espurias. 
¿Por que o castelanismo triunfou máis nestas zonas ca noutras? ¿É que nas áreas correspondentes aos partidos xudiciais de Xinzo, Verín, Allariz, Ourense e Viana, por un lado, e Vilalba, Lugo, Mondoñedo, Ribadeo e Viveiro por outro, a presión castelanizadora dos xulgados respectivos foi máis forte ca noutras zonas? Para responder esta pregunta cumpriría un estudo comparativo das restantes formas castelanizadas para comprobar se hai maior concentración nesas áreas, e mais tamén un estudo intensivo dos rexistros nalgún concello en concreto para corroborar se efectivamente hai unha acción castelanizadora consciente. Para a castelanización dos apelidos, ata o momento téñense dado aproximacións cuantitativas e lingüísticas, pero faltan estudos específicos que marquen as liñas mestras (xeográficas e cronolóxicas) de actuación.

En certa maneira hai que poñer en relación o proceso de castelanización co da estandarización dos apelidos. No dominio lingǘstico do español e no portugués, este proceso funcionou máis eficazmente, o que incidiu nunha menor variabilidade de formas. En Galicia os esforzos de regularización formal, normalmente non planificados, e suponse que dependentes da vontade dos funcionarios que encabezaban os diferentes rexistros, viñeron acompañadas moitas veces dunha decidida vontade castelanizadora. De maneira que agora podemos atopar como variantes dun apelido unha forma maioritaria (Louzao), unha variante dialectal (Louzán), a forma castelanizada (Lozano), e en ocasións, de forma moi minoritaria, incluso algunha variante fonética (Louz̧au, 10 ocorrencias).

3. A información que proporcionan as áreas xeográficas dos apelidos Martís/Martins van na mesma dirección. O patronímico correspondente a Martinus (Martiño ou Martín, segundo estivese ou non en posición proclítica) foi extraordinariamente abundante na Idade Media (estivo entre os 10 primeiros dos século IX ao XIII: vid. Boullón 1999: 82-83). Como é habitual nos nomes de alta frecuencia, adoitaba representarse mediante unha abreviatura, tendencia que foi aumentando a medida que avanzaba a Idade Media, de maneira que contra o século. $\mathrm{XV}$ apenas se constata de forma plena, isto é, sen abreviar. A maioría delas son abreviaturas por contracción (mary, mrtz, mrv, mrv, mz, ms, mrt), e hai algunha por suspensión (mart), sempre cun sinal de abreviación por riba da palabra. Porei algúns exemplos tirados de diversas coleccións documentais, desde o século XIII ata o XV, coa convención usual de indicar en cursiva o que son desenvolvementos do editor. 


\section{- mart}

Johã Martins de Creende (a.1258 CDMaia 71)

Munjn Martinz, (a.1274 [or.] CDRamirás 392)

- marz

Pedro Miguelez e a uossa moler Maria Martinz (a.1314 CDMaia 151)

- mrtz

Domingo Martinz da Decolada (a.1302 [or.] CDRamirás 455)

Costança Martinz (a.1396 [or.] CDFerreira 101)

- mrts

Affonso Martins ([clérigo] a.1366 [or.] CDRamirás 520)

Fernã Martins filo de Martino da Gurgulla (a.1427 [or.] CDFerreira 189)

- mrtiz

Siluestre Martinz (a.1273 [or.] CDRamirás 386)

- $\mathrm{mrt}$

Joã Martinz dito Pulga (a.1266 TLourenzá 170)

Pedro Martins notario del rey don Ffernãdo enos coutos de Sobrado (a.1300 CDMaia 51)

Johan Martiuss morador de Juño ffillo de Martin Monýs de Caamano (a.1342 [or.] DocNoia $17 \mathrm{n}^{\circ} 4$ )

Bernal Martiũs coẽgo (a.1390 [or.] LTenzaHórreo 7R)

Martin Serpe ffillo de Vasco Martĩus Serpe (a.1401 [1414-1500] TBieito-

Santiago 41)

- mrrz

Aldonça Marrtiz (a.1305 [or.] CDRamirás 456)

- mrrs

Johan Marrtis de Freytuxe (a.1379 [or.] CDFerreira 89)

- mrr

Estéuão Marrtiis de Gyssamõde (a.1342 [or.] DocNoia 16n³)

- mrtis

Maria Martis (a.1380 [or.] CDRamirás 534)

- mrz

Johan Martinz dito Fame (a.1298 CDMaia 207 [Poio-Po])

Martino Martiz (a.1299 [or.] CDFerreira 40)

- $\mathrm{mrs}$

Mor Martins (a.1346 [or.] CDRamirás 497)

Pedro Martis notario plublyco por ell rey eno alffoz do Castelo de Tebra (a.1299 CDMaia 215)

- $\mathrm{mz}$

Martin Martĩ fillo de Domingo Martinz de Lezellães (a.1301 CDMaia 219

[A Caniza-Po])

Domingo Martĩz e a vosa moller Maria Martĩz. (a.1278 [or.] CDRamirás 414

- $\mathrm{ms}$

Lopo Martins de Çidrãas (a.1457 LNotasRianxo 1445) 
Son moi poucos, logo, os casos en que este apelido aparece por extenso. Outra cousa é como o vexamos nas coleccións documentais editadas, pois moitos dos editores non indican que están desenvolvendo unha abreviatura. Os exemplos localizados e reproducidos a seguir proceden de fontes editadas en que si se seguiu ese criterio, o da indicación en cursiva das abreviaturas (ou, se non, foron comprobadas as lecturas por min persoalmente):

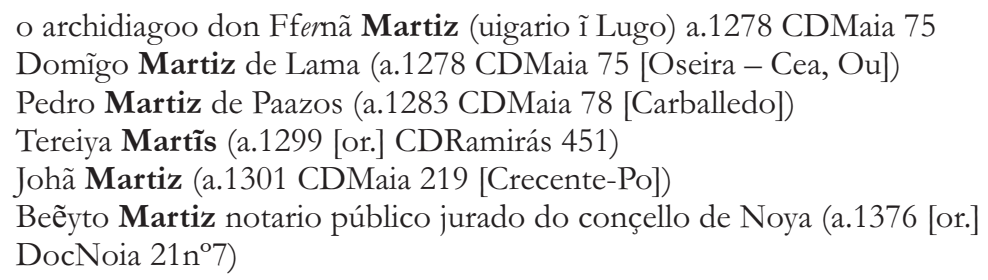

Este excurso sobre as abreviaturas textuais nos documentos medievais non é un mero pretexto de erudición filolóxica, senón que o traio a colación porque considero que tivo que ver coa fortuna (ou desfortuna) posterior do apelido. O galego comezou a desaparecer dos documentos notariais a finais do século $\mathrm{XV}$, coincidindo co inicio da instalación da práctica dos rexistros parroquiais, o que se fixo xa en castelán. De maneira semellante ao que fan hoxe algúns editores de textos medievais pouco escrupulosos, posiblemente os escribas daquela, xa alfabetizados en castelán (desde o século XV debían pasar un exame de suficiencia en castelán), desenvolvían esa abreviatura coa forma castelá: escribían Martínez: Creo que iso propiciou a presenza contundente da forma castelá, fronte á forma galega, que se foi volvendo residual (hoxe representa un $0,9 \%$ con respecto á outra). Paréceme que é máis fácil adquirir o hábito de desenvolver unha abreviatura dunha maneira determinada que cambiar unha forma extensa galega por outra en castelán. Iso non pasou con outros patronímicos, tamén moi frecuentes, que non presentaban a distorsión da abreviatura, coma Vázquez, Méndez, Paz (ou Páez) ${ }^{6}$ ou Estévez: Soamente aquelas que teñen unha presenza

\footnotetext{
6 Aínda que este patronímico presentaba unha problemática en parte semellante, pois era moi habitual a súa representación coas abreviaturas plz ou $p l$, herdadas da tradición gráfica latina. No entanto, creo que aquí a homonimia do resultado Paz co
} 
cuantitativamente importante poden considerarse castelanizacións: no cadro seguinte vemos que están nese caso Martínez, sobre todo, e en menor medida Menéndez (un 5,6\% con respecto á forma propia, Méndez) e Peláez (o mesmo número de formas ca Páez, pero un 2,6\% con respecto a todas as variantes galegas dese ítem). Nos outros ítems son as formas casteláns as que se poden considerar moi minoritarias.

\begin{tabular}{|l|r|l|rr|}
\hline \multicolumn{2}{|l|}{ Formas galegas } & \multicolumn{3}{|c|}{ Formas castelás/castelanizadas } \\
\hline MARTINS & 800 & MARTÍNEZ & 113.431 & $(99,1 \%)$ \\
\hline PARTIS & 207 & & & \\
PÁEZ & 531 & PELÁEZ & 531 & $(2,6 \%)$ \\
PAIS & 17.695 & & & \\
PÁIZ & 2.388 & & & \\
\hline ESTÉVEZ & 4 & & & \\
\hline MÉNDEZ & 22.734 & MENÉNDEZ & 1.268 & $(5,6 \%)$ \\
\hline VÁZQUEZ & 101.799 & VELÁZQUEZ & 256 & $(0,26 \%)$ \\
\hline
\end{tabular}

No que respecta á distribución cartográfica deste apelido, a forma máis etimolóxica, Martins, ten representación ao longo e largo de toda a xeografía galega, e a súa maior densidade non ten que ver coa actual distribución dos plurais en -ns/-s (tipo pantalóns/pantalós), como se pode ver se superpomos un mapa ao outro.

A maior concentración dos apelidos está no sur de Galicia, isto é, na zona limítrofe de Portugal. Non é casual, por suposto. En Portugal non houbo a interferencia do castelán e a forma que se regularizou foi Martíns. Debeu ser a influencia desa forma no país veciño a que asegurou a permanencia da forma tradicional galega. Os efectos de estandarización antroponímica eliminaron en Portugal outras posibles solucións dialectais, que, no entanto, si tiveron os seus continuadores en Galicia. A forma Martís (que non aparece no Dicionário de Machado

substantivo común influíu para que non se identificara co patronímico de Paio (Pelayo en castelán), e por tanto se mantivese inalterado. O patronímico máis recoñecible, Páez, ten exactamente o mesmo número de ocorrencias cá forma castelanizada, Pelaez. (531), o que indica que, aínda que en menor medida, tamén sufriu un proceso de castelanización. Por último, a variante Pais era xa dificilmente identificable co apelido castelán correspondente, o que a preservou mellor. 
[1984]), documéntase en Galicia, pero non só onde sería esperable, na área central de Galicia (onde só se atesta no Saviñao e na área metropolitana da Coruña), senón que presenta a súa concentración máis alta na península da Barbanza, na Baña e en Negreira (A Barcala), área de plural en -ns nos singulares en - $n$ (pantalóns). Está claro que o patronímico non é un plural, pero hai topónimos que coa mesma terminación fonética, sexan ou non plurais, se adaptan conforme á regra morfolóxica dos plurais (cf. Aríns en Santiago < Aris < Ariz < Alarici, HGNB 6.13).

Creo, logo, que as formas en -ins son máis abundantes e están repartidas por toda Galicia porque aquí operou un factor, a presión uniformizadora de escrita, que non existía no léxico común, pois nestas alturas (a partir do XVI) o seu desenvolvemento era case exclusivamente oral.

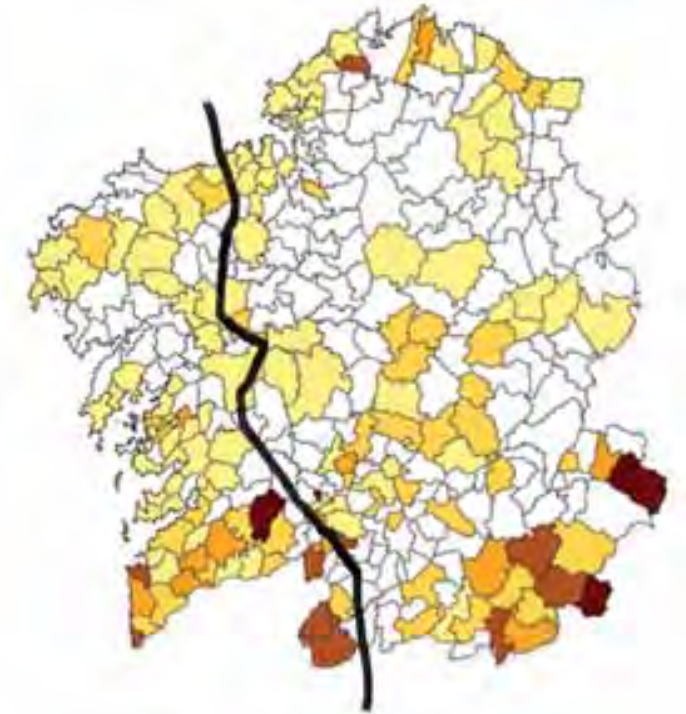

Mapa 9. Distribución actual do apelido Martíns e isoglosa da terminación do plural -ns ( $A L G a)$

O apelido, non obstante, estaba sometido a unha presión uniformizadora, que, por un lado, motivou o establecemento da forma castelá (Martínę), e, por outro, consentiu a permanencia da forma medieval (Martins), independentemente da solución oral para os plurais en -in (que non son moi numerosos, sobre todo en comparación cos en -án e en -ón). Por outro lado, a forma máis innovadora e menos etimolóxica (pois perdera totalmente a nasal orixinal) maniféstase esporadicamente por toda Galicia, como de- 
mostra a presenza do topónimo Os Martices, plural de Martiž , non só na área que hoxe corresponde a pantalós, senón tamén na área occidental de Galicia (Cabana de Bergantiños, Vilagarcía e Cotobade).

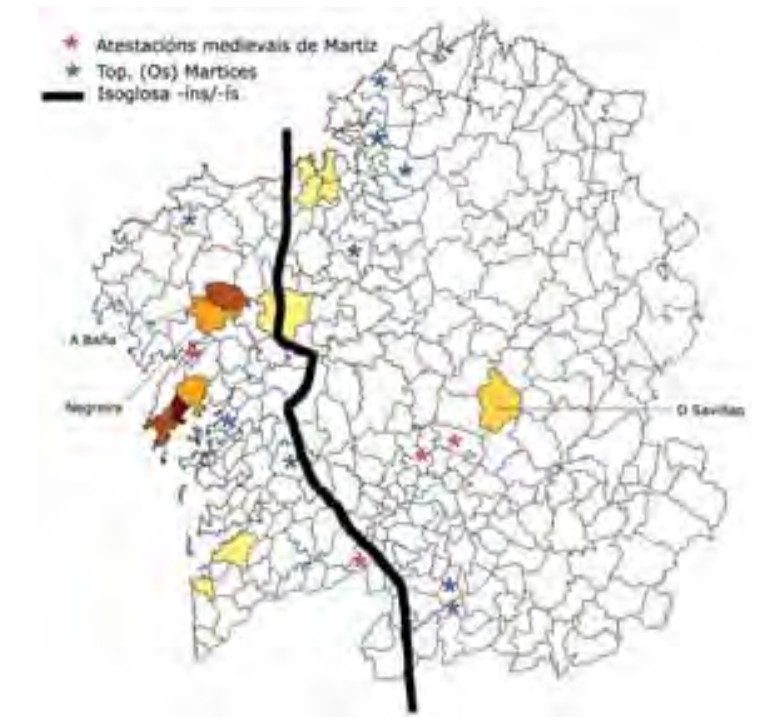

Mapa 10. Distribución actual do apelido Martís, con indicación do topónimo $(O s)$ Martices e isoglosa da terminación -ns (ALGa)

En definitiva, a existencia do topónimo Os Martices e mais esa área compacta de Martís no bloque occidental parecen indicar que o plural en -ís procedente de -INES puido existir na actual área de -íns. As atestacións medievais que posuímos non son concluíntes por tratarse na súa maior parte de resolución de abreviaturas, pero as poucas que seleccionamos por consideralas fiables revélannos un Martiz de Noia, actual área de plural en -ns. Por outro lado, son poucos os estudos feitos sobre dialectoloxía medieval que expliquen a presenza destas formas nesta área; hai, sobre todo, aproximacións cronolóxicas, que dan fe do temperán do fenómeno da desnasalización (Lorenzo 1988: 315; Mariño 2002). A única tentativa de descrición diatópica que parte de datos fiables, é dicir, dunha boa edición textual, a de Maia, foi feita

\footnotetext{
7 Formación toponímica semellante a Os Dices, Os Martiños, con dez ocorrencias, nos concellos de Barreiros (Lu), Cabana de Bergantiños, Cabanas, Mesía, Monfero, Valdoviño (Co), Cotobade, Vilagarcía de Arousa (Po), Porqueira e Rairiz de Veiga (Ou).
} 
nunha altura en que aínda non estaban difundidos os estudos de dialectoloxía galega moderna nin o ALGa, e por tanto tampouco puido establecer comparacións máis que aproximativas:

Existiría já no galego medieval uma repartição geográfica dos dois tipos de terminação com e sem nasal? Ou ofereceria a língua, nessa época, diferentes possibilidades, tendo ocorrido posteriormente a fixação em cada uma das soluções de acordo com as regiões? A localização geográfica das formas [...] parece permitir concluir que existiria já uma distribuição geográfica dos dois tipos de variantes. Assim, a variante -oos surge em documentos da província de Lugo (cf. 1475 L48) ou do norte da província da Coruña (cf. 1516 C18), localizados, portanto, dentro da área actual de -ós; quanto às variantes gráficas -õos, -õons e -ons, elas parecem ocupar uma área mais vasta do que a da moderna solução -óns, penetrando muito mais para oriente do que acontece actualmente: podem registrar-se na metade ocidental da província de Lugo segundo unha linha que passa por Lourenzá, Lugo e Monforte (CDMaia: 608).

Como vemos, aquí apúntase o contrario dos datos que nós presentamos: testemuños medievais en -is en área actual de -ins, fronte a testemuños medievais de -óns en área actual de -ós. Son poucos datos para tirar conclusións definitivas sobre os resultados dialectais históricos da desnasalización nese contexto fonético, tendo en conta ademais, para os datos procedentes dos apelidos, que sempre puideron producirse migracións que producisen a súa dispersión e posterior propagacións en áreas concretas. Pero os datos toponímicos (Os Martices) apuntan no mesmo sentido. En calquera caso, cómpre chamar a atención sobre a necesidade de estudar os datos onomásticos á hora de confeccionar un mapa dialectolóxico diacrónico que dea conta da evolución dos fenómenos fonéticos ou morfolóxicos.

\section{CONCLUSIÓNS}

Da análise da distribución areal dos apelidos actuais, xunto coa das súas documentacións históricas e o seu número de ocorrencias, infírense as peculiaridades dos seus movementos de expansión, pois están condicionados pola súa orixe: se son topónimos (polixenéticos ou monoxenéticos), se son patronímicos ou se son delexicais. A partir deles pódense tirar diferentes tipos de información. 
- As vías de difusión dos apelidos monoxenéticos, especialmente se teñen a súa orixe nun topónimo único (coma o caso de Boullón e Xove), mostran os movementos de poboación, polo que son de interese tamén para os estudos demográficos e históricos.

- Nos apelidos de tipo léxico vemos como a carga semántica pode influír na súa difusión, ou mesmo na súa desaparición en determinadas áreas, pois a interdición funciona aquí máis ca no léxico común, como vemos no caso de Cochón.

- A coincidencia coas isoglosas léxicas non é casual: a difusión polas vías de comunicacións, condicionada polos impedimentos xeográficos, é a mesma: os homes, as súas palabras e os apelidos viaxan xuntos. Porén, o propio carácter fosilizado de moitas formas vixentes nos apelidos e perdidos no léxico común fan que poñan de relevo estadios da lingua anteriores ao actual ou que dean indicios sobre a difusión de certos fenómenos fonomorfolóxicos (coma a desnasalización en posición final, como en Martins/Martís, ou a terminación -ao/-án en Louzán/Louzao), ou fonéticos, coma a isoglosa do -s/-zimplosivo (Eiriz/Eiris).

- Outro elemento que compre ter en conta é a influencia da regularización da escrita. Hai maior resistencia das formas máis etimolóxicas: os rexistros escritos posiblemente fosen refractarios aos cambios que non implicasen a castelanización. Por iso as formas máis antigas poden indicar non soamente a súa presenza en determinadas zonas senón tamén que, despois de producirse o cambio lingüístico, os apelidos se mantiveron sen cambiar. Independentemente da deriva da lingua común, a presión uniformizadora motiva a resistencia dos Louzao, ou a forma Martins na raia con Portugal.

- En relación con isto, está a presión do castelán, especialmente forte a partir do século XVI: isto produciu a aparición de formas castelanizadas que en ocasións superan cuantitativamente as formas xenuínas, como é o caso de Lozano ou Martínez fronte a Louzao/Louzán ou Martíns/Martís. Cumpriría unha nova política lingüística para contribuír a restaurar as deturpacións producidas ao longo dos últimos séculos no corpus dos nosos apelidos. 